\title{
Intracellular Signaling and Genetic Reprogramming during Agonist-Induced Hypertrophy of Cardiomyocytes ${ }^{a}$
}

\author{
H. A. A. VAN HEUGTEN, ${ }^{b}$ H. W. DE JONGE, ${ }^{b}$ \\ K. BEZSTAROSTI, ${ }^{b}$ H. S. SHARMA,$^{c}$ P. D. VERDOUW,$^{d}$ \\ AND J. M. J. LAMERS ${ }^{b}$ \\ Departments of ${ }^{b}$ Biochemistry and $P$ Pharmacology and ${ }^{d}$ Thorax \\ Centre, Cardiovascular Research Institute COEUR \\ Faculty of Medicine \& Health Sciences \\ Erasmus University Rotterdam \\ P. O. Box 1738 \\ 3000 DR Rotterdam, The Netherlands
}

\section{INTRODUCTION}

Cardiac myocytes stop dividing shortly after birth and subsequently the heart grows by enlargement of individual cells, a process that can be observed in vitro as well. ${ }^{1}$ However, growth of individual cardiomyocytes can also be observed in the adult heart, a process called hypertrophy. Chronic hemodynamic overload of the heart by, e.g., infarction, hypertension or volume or pressure overload ultimately leads to hypertrophy of the left ventricular wall. The hypertrophy process involves induction of transcription of specific contractile as well as noncontractile protein genes resulting in growth as well as change in contractile function of the cardiomyocyte. ${ }^{2,3}$ This allows the heart to maintain normal beat-to-beat volume under the circumstances mentioned above. Although only limited evidence was presented for their importance during in vivo development of hypertrophy, ${ }^{4-7}$ hormonal and mechanical stimuli are thought to be the initial signals that trigger the onset of cell growth. The evidence for the involvement of hormonal and mechanical signals in the induction of hypertrophy mainly comes from in vitro models employing cultured neonatal cardiomyocytes. Here it was shown that induction of hypertrophy is accompanied by activation of the phosphoinositide (PI) cycle and by rapid stimulation of transcription of so-called immediate early genes, transcription factors, ultimately leading to rearrangement of gene expression of structural proteins in the cardiomyocyte. Recently, studies of hypertrophy were also performed on cultured adult cardiomyocytes, ${ }^{8-11}$ confirming results from the neonatal cardiomyocyte model. In this review we focus on the influence of these hormonal and mechanical signals that activate the PI cycle during development of hypertrophy in the model of cultured cardiomyocytes and the ultimate outcome

" Parts of this work were supported by the Netherlands Heart Foundation (Grant No. 92.081) and the Netherlands Organization for Scientific Research (NWO) (Grant No. 900516-127.) 
of hypertrophic stimulation for the cardiac myocyte. The last section deals with some of our most recent results.

Some of the signals that trigger a hypertrophic response are not transduced through activation of the PI pathway. These include $\beta$-adrenergic stimulation that activates adenylate cyclase, ${ }^{12}$ while several growth factors like fibroblast growth factor, ${ }^{13,14}$ insulin-like growth factor-I, ${ }^{15,16}$ thyroid hormone and transforming growth factor $\beta^{13}$ were also shown to activate growth-like responses. Extracellular signals that stimulate the PI cycle can also lead to growth of the cardiomyocyte, and in the last years more and more agonists of this type were identified. These include the $\alpha_{1}$-adrenergic agonist phenylephrine (PHE), ${ }^{17}$ angiotensin II (AngII), ${ }^{18}$ endothelin-1(ET-1) $)^{19,20}$ and $\alpha$-thrombin. ${ }^{21}$ Furthermore, stretching of cultured cardiomyocytes leads to increased PI cycle activity and ultimately to hypertrophy. ${ }^{22}$ Increased contractile activity of cardiomyocytes also induces hypertrophy, ${ }^{23.24}$ but the question might be asked whether this is an independent mechanism or is transduced through increased stretching of the cells. We might even envisage $\beta$-adrenergic induction of hypertrophy as being partly the result of an increase in beating frequency of the myocytes.

\section{Stimulation by $\alpha_{1}$-Adrenergic Agonist}

$\alpha_{1}$-Adrenergic stimulation of phosphoinositide hydrolysis in cardiomyocytes is mediated through the $\alpha_{1 \mathrm{~A}}$-adrenergic receptor ${ }^{25}$ that is coupled to phospholipase $\mathrm{C}_{\beta}$ through the GTP-binding protein $\mathrm{G}_{\mathrm{q}, 11} .{ }^{26}$ Blocking the $\alpha_{1 \mathrm{~A}}$-adrenergic receptor led to inhibition of $\alpha_{1}$-induced hypertrophy, in contrast to treatment with $\alpha_{1 B^{-}}$ adrenergic receptor blockers. ${ }^{25}$ Blocking the $G_{\mathrm{q}, 11}$ function results in inhibition of $\alpha_{1}$-adrenergic-mediated hypertrophy as well. ${ }^{26}$ These results directly implicate the PI cycle as an important intermediate in the signal transduction cascade leading to induction of cell growth. However, we have to be aware of the fact that $\alpha_{1}$ adrenergic agonist is translocated to the nucleus where the receptor is also localized ${ }^{27}$ suggesting a direct role of the receptor-agonist complex in regulation of gene expression. More distal elements of the signaling cascade involved in hypertrophy induction by catecholamines have also been identified. $\alpha_{1}$-Adrenergic stimulation of cardiomyocytes results in increased diacylglycerol levels. ${ }^{28,29}$ Probably as a result of this, activation and translocation of protein kinase $\mathrm{C}$ to membranes and myofilaments occurs. ${ }^{30-33}$ Activation of protein kinase $\mathrm{C}$ by phorbol ester is sufficient to give several hypertrophic responses, ${ }^{32,34,35}$ as was also elegantly demonstrated by protein kinase $\mathrm{C}$ transfection studies. ${ }^{32,36}$ However, activation of protein kinase $\mathrm{C}$ is not the only factor involved in induction of hypertrophy. Taking expression of atrial natriuretic factor (ANF) as parameter of the degree of hypertrophy (see below), it was shown that inhibition of protein kinase C activity resulted in a $75 \%$ decline in hypertrophic response to $\alpha_{1}$-adrenergic stimulation. ${ }^{28}$ On the other hand, inhibition of $\mathrm{Ca}^{2+} /$ calmodulin-regulated kinases completely blocked development of hypertrophy, in agreement with the requirement for calcium of the hypertrophy process. The involvement of $\mathrm{Ca}^{2+} /$ calmodulin-regulated processes in induction of cell growth is further substantiated by a study in which overexpression of calmodulin led to induction of hypertrophy as well as hyperpla- 
sia. ${ }^{37}$ Other kinases that might be involved in transduction of the extracellular signal to the nucleus are MAP(kinase) kinases, which are thought to play an important role in growth-related processes. These MAP(kinase) kinases are activated by $\alpha_{1}$-adrenergic stimulation of cardiomyocytes. ${ }^{38}$ However, direct evidence for the involvement of MAP kinases in the signaling pathway connecting the $\alpha_{1}$-adrenergic receptor to nuclear events has not been obtained. Coordinated expression of several genes takes place as a result of $\alpha_{1}$-adrenergic stimulation. The hypertrophic response after $\alpha_{1}$-adrenergic stimulation was inhibited by mutated, inactive Hras proto-oncogen $e^{39}$ suggesting that tyrosine kinases are involved in this response, independent of activation of the PI cycle. ${ }^{26}$ Early and transient responses include transcription of so-called immediate early genes, encoding known or putative transcription factors. The first proto-oncogene that was shown to be induced by $\alpha_{1}$ adrenergic stimulation was c-myc. ${ }^{40}$ However, constitutive overexpression of cmyc in a strain of transgenic mice did not lead to a hypertrophic response but led to growth of the heart by hyperplasia suggesting that it is not directly involved in growth of the heart by cell enlargement. ${ }^{41}$ Other proto-oncogenes that are expressed upon $\alpha_{1}$-adrenergic stimulation are c-fos, c-jun and EGR-1. ${ }^{42}$ The c-fos/ c-jun heterodimer binds to AP-1 DNA consensus sequences resulting in activation of transcription of genes containing these elements, e.g., in the ANF gene. ${ }^{43}$ The presence of EGR-1 protein is a prerequisite for agonist-induced hypertroph $y^{44}$ as will be discussed below for ET-1. At a later stage of hypertrophy, protein synthesis increases, ${ }^{17,45,46}$ accompanied by enhanced transcription of several genes. These include the contractile protein myosin light chain-2 that is assembled into organized sarcomeric units. ${ }^{47,48}$ However, embryonic genes ANF, ${ }^{28.48 .49}$ skeletal $\alpha$ actin $^{50-52}$ and $\beta$-myosin heavy chain ${ }^{53}$ were induced as well resulting in a change in phenotype of the cardiomyocyte. This change is further reflected by a lack of induction of cardiac $\mathrm{Na}^{+}$channel expression. ${ }^{48}$

\section{Stimulation by ET-1}

Stimulation of cardiomyocytes with ET-1 results in activation of phospholipase $\mathrm{C}$, as was the case for PHE, again leading to increased inositolphosphate production ${ }^{54}$ and diacylglycerol levels. ${ }^{19,29}$ This effect is probably mediated by the ETA receptor. ${ }^{6,55,56}$ Given the important role of the PI cycle in activation of the hypertrophy process, ${ }^{11}$ it is not surprising to see that the hypertrophic responses of ET-1 and PHE are remarkably similar. After stimulation with ET-1, protein kinase $\mathrm{C}$ is activated ${ }^{33}$ as well as MAP(kinase) kinase $^{57}$ and MAP kinase. ${ }^{38,57}$ The activation of protein kinase $\mathrm{C}$ by ET-1 is necessary for induction of hypertrophy as judged by inhibition of ET-1-induced increase in protein synthesis after incubation with a protein kinase C inhibitor. ${ }^{58}$ Activation of MAP kinase is partly brought about by the activity of protein kinase $\mathrm{C}$ isotypes that are stimulatable by phorbol ester. However, as downregulation of these isozymes by prolonged incubation of cultured cardiomyocytes with phorbol ester did not result in total inhibition of ET-1-induced MAP kinase activity, ${ }^{57}$ this hormone might also activate so-called atypical protein kinase $\mathrm{C}$ isozymes that do not require $\mathrm{Ca}^{2+}$ and/or diacylglycerol for activation. Moreover, as cultured cardiomyocytes contain protein kinase 
C- $\alpha$ and $-\delta,{ }^{57}$ isozymes that are not found in the intact adult heart, ${ }^{33}$ the relative importance of both signaling pathways remains to be determined. As was the case for $\alpha_{1}$-adrenergic stimulation, incubation with ET-1 activates the immediate early gene program. Here, c-fos and EGR-1 were induced within 30 min after stimulation and decreased again after 1 hour. ${ }^{10,19,59}$ The expression of EGR-1 is of prime importance for development of hypertrophy; blocking translation of the EGR-1 mRNA by an antisense oligonucleotide completely inhibits ET-1-induced stimulation of protein synthesis, an indicator of hypertrophy. ${ }^{44}$ Rearrangement of gene expression was again noticed; the transcription of the embryonic gene ANF ${ }^{19,29}$ as well as of the $\alpha$-actin, and troponin I genes were stimulated. ${ }^{60}$ Myosin light chain- 2 gene transcription was also stimulated, ${ }^{60}$ and increased amounts of myosin light chain-2 were assembled into organized contractile units. ${ }^{19}$ In contrast to $\alpha_{1}$ adrenergic stimulation, ET-1 not only increased transcription of the embryonic myosin heavy chain $\beta$-isozyme but also of the adult $\alpha$-form. ${ }^{61}$ This suggests that differences in signal transduction pathways leading to hypertrophy exist between the $\alpha_{1}$-adrenergic agonist and ET-1. It was already shown that exposure of cardiomyocytes leads to partial homologous desensitization of the PI cycle activity, a phenomenon not present during $\alpha_{1}$-adrenergic stimulation. ${ }^{29,54}$ Whether this is the underlying mechanism that is responsible for the difference in myosin heavy chain isozyme expression as described above and the rapid decrease of ET-1-induced ANF mRNA levels ${ }^{29}$ remains to be determined. During development of hypertrophy the amount of RNA in the cells increases as well as protein synthesis. ${ }^{11,20}$, ${ }_{58,60}$ Conflicting results were reported concerning the role of extracellular $\mathrm{Ca}^{2+}$ in stimulation of protein synthesis by ET-1. In one study, a $\mathrm{Ca}^{2+}$ blocker had no effect, ${ }^{60}$ while the group of Suzuki and co-workers showed that the same $\mathrm{Ca}^{2+}$ channel blocker partly inhibited ET-1-induced increase in protein synthesis. ${ }^{20,58}$ On the other hand, it was shown that an increase in intracellular $\mathrm{Ca}^{2+}$ leads to a temporal stimulation of transcription of the myosin light chain-2, $\alpha$-actin and troponin genes, ${ }^{60}$ while ET-1-stimulated ANF release was also partially $\mathrm{Ca}^{2+}$ dependent. ${ }^{62}$ Together with the results concerning $\mathrm{Ca}^{2+}$ dependence of the $\alpha_{1}$-adrenergic induction of hypertrophy, we would like to suggest that $\mathrm{Ca}^{2+}$ is also important for ET-1-induced hypertrophy. In this respect it is interesting to note that we recently showed that intracellular free $\mathrm{Ca}^{2+}$ has a feed-forward stimulatory effect on phospholipase $\mathrm{C}$ when the enzyme is stimulated with ET-1 or PHE. ${ }^{63}$ Although it is thought that endothelial cells are the major source of endothelin, it is important to mention that ET-1 is produced and secreted by cardiomyocytes as well, ${ }^{64}$ suggesting that autocrine/paracrine mechanisms of induction of hypertrophy might be important too.

\section{Stimulation by AngII}

Another peptide hormone that was shown to induce hypertrophy is AngII, ${ }^{4,18}$ acting through the $\mathrm{AT}_{1}$ receptor. ${ }^{65}$ AngII provokes phospholipase $\mathrm{C}$ activity that is rapidly desensitized. ${ }^{66,67}$ However, the increase in DAG is more prolonged, and it was shown that AngII also activates phospholipase D resulting in degradation of phosphatidylcholine and formation of diacylglycerol through phosphatidic 
acid ${ }^{67.68}$ Probably as a result of this, protein kinase $\mathrm{C}$ is activated. Furthermore, cyclic-AMP levels were increased and arachidonic acid production was stimulated showing that AngII activates several signal transduction pathways at the same time. As a result of protein kinase $C$ activation the expression of $c$-fos was transiently stimulated in a $\mathrm{Ca}^{2+}$-dependent manner. The immediate early genes $\mathrm{c}$ jun, jun-B, EGR-1 and c-myc were also transiently expressed.9.10.65 Again, the expression of embryonic genes was induced; ANF as well as skeletal $\alpha$-actin mRNA was increased within $6 \mathrm{hrs}$ of stimulation with AngII. As research into the hypertrophic effect of AngII is relatively young, studies on expression of contractile genes are not yet available. We have to keep in mind that prolonged incubation of cardiomyocytes leads to stimulation of ET-1 synthesis and secretion by cardiomyocytes. ${ }^{69}$ This opens the possibility that part of the AngII-mediated responses are brought about by ET-1.

Stretching of cardiomyocytes also results in activation of phospholipase $C$ and phospholipase D, and release of arachidonic acid and ultimately leads to hypertrophy. ${ }^{70-74}$ This is preceded by a short-lived increase in the inositolphosphate level and prolonged diacylglycerol accumulation, as well as protein kinase C and MAP kinase activation. ${ }^{73}$ The MAP kinase activation was partially dependent on $\mathrm{Ca}^{2+}$ and the presence of phorbol ester-stimulatable protein kinase $\mathrm{C},{ }^{73,75}$ and although tyrosine kinases were activated, ${ }^{73}$ they were not involved in activation of MAP kinases, ${ }^{75}$ suggesting a dual pathway of activation and a role for atypical protein kinase $\mathrm{C}$ isozymes. The immediate early gene $\mathrm{c}$-fos was induced in a protein kinase C-dependent manner, ${ }^{73}$ and c-jun, $c$-myc and EGR-1 were induced as well. ${ }^{9,71}$ At a later stage of hypertrophy induction, the fetal cardiac genes ANF, $\beta$-MHC and skeletal $\alpha$-actin were expressed. ${ }^{71}$ These data are reminiscent of the multiple pathways that are activated by AngII and it was indeed shown that upon stretch, AngII is released by cardiomyocytes in culture. ${ }^{76,77}$ The involvement of AngII in stretchinduced hypertrophy was confirmed by a study where stretch-induced hypertrophy could be blocked by an AngII receptor antagonist. ${ }^{7}$ Furthermore, ion-channels and contractile activity were shown not to be involved in transduction of stretchsignals to the nucleus. ${ }^{78}$ The control of gene expression during mechanical stress was recently reviewed. ${ }^{79}$ At this stage it is important to stress again that AngII also has an effect on ET-1 levels; AngII induces ET-1 precursor mRNA in cardiomyocytes in a protein kinase $\mathrm{C}$-dependent fashion. ${ }^{69}$ This depicts a situation where stretching of the cardiomyocytes directly activates multiple signaling pathways through the stretch-induced release of AngII followed by activation of phospholipase $\mathrm{C}$ by ET-1 that is produced and released by cardiomyocytes under influence of AngII.

\section{Stimulation by Thrombin}

A fourth receptor that is coupled to induction of hypertrophy through activation of the PI cycle is the thrombin receptor. ${ }^{21,80}$ Actually, it is a receptor for its own $\mathrm{N}$-terminal peptide that is cleaved from the receptor by thrombin. Stimulation of cardiomyocytes with thrombin as well as with the $\mathrm{N}$-terminal peptide leads to morphological and genetic changes that are reminiscent of hypertrophy: cells are 
enlarged and contain highly organized sarcomeric units while ANF expression is induced in a dose-dependent manner. The signal transduction pathway involves both protein kinase $\mathrm{C}$ and tyrosine kinase activation. The relative importance of thrombin in in vivo induction of hypertrophy remains to be determined as cardiomyocytes are normally separated from circulating thrombin by the vessel wall.

\section{Other Stimuli}

We have to be aware of the fact that activation of phospholipase $\mathrm{C}$ not only occurs through G-protein-coupled receptors, but that tyrosine kinases can also lead to increased PI cycle activity through phosphorylation and activation of the phospholipase $\mathrm{C} \gamma$-isozyme. Tyrosine kinase activity is an inherent property of a large amount of receptors, e.g., the EGF, insulin, and FGF receptor families. ${ }^{81}$ Indeed, FGF activates tyrosine kinases and MAP kinases ${ }^{57}$ and induces hypertrophy. ${ }^{13,14}$ Whether other receptor tyrosine kinases also induce hypertrophy remains to be determined. Hypertrophic responses like induction of ANF expression and stimulation of myosin light chain- 2 gene expression can also be brought about by electrical stimulation of contraction of cardiac myocytes, independent of activation of protein kinase $\mathrm{C}$ or $\mathrm{A}$ but depending on $\mathrm{Ca}^{2+}$ fluxes across the membrane and calmodulin activity. ${ }^{49}$ This suggests a role for $\mathrm{Ca}^{2+} /$ calmodulin-dependent kinases, as was described above. Furthermore, as many agonists like PHE and ET-1 also stimulate contraction of cells in culture, part of the hypertrophy caused by these agonists might be induced by increased contraction, as suggested by the $\mathrm{Ca}^{2+}$ dependence of many of the intracellular events.

\section{Genetic Reprogramming During Cell Growth}

As described above, induction of cell growth results in induction or increase in transcription of several genes. ${ }^{2,3}$ These agonist- or stretch-induced alterations in cardiomyocyte phenotype are reminiscent of the changes during in vivo cardiac remodeling following cardiac overload. These changes lead to reexpression of fetal genes, e.g., $\beta$-myosin heavy chain, skeletal $\alpha$-actin and ANF. The reexpression of $\beta$-myosin heavy chain leads to a larger amount of the homodimer $V_{1}$ isomyosin and results in a slower rate of ATP cycling by myosin and thus a lower rate of contraction in the hypertrophied heart. On the other hand, this improves efficiency and economy of contraction, suggesting an adaptive response.

It is important to stress that in the in vivo situation, enzymes that take part in $\mathrm{Ca}^{2+}$ homeostasis are also involved in phenotypic changes of the hypertrophied heart. For instance, the sarcoplasmatic reticulum $\mathrm{Ca}^{2+}$ ATPase as well as its regulatory protein phospholamban are not induced or may even be downregulated during development of hypertrophy, resulting in aberrant $\mathrm{Ca}^{2+}$ handling in the hypertrophied heart impairing relaxation. ${ }^{82,83}$

\section{Differences in Signal Transduction and Magnitude of Hypertrophy between Agonists That Activate the PI Cycle}

Only a limited number of studies have directly compared signal transduction and induction of hypertrophy of agonists that activate the PI cycle. Using the 
model of cultured neonatal rat ventricular myocytes we therefore compared the effects of AngII, ET-1 and the $\alpha_{1}$-adrenergic agonist phenylephrine (PHE). Although the second messenger inositol $(1,4,5)$ tris-phosphate was not detectable due to fast dephosphorylation, ${ }^{84}$ ET-1 and PHE were equipotent in activation of the PI cycle, but the ET-1-induced production of inositol phosphates was subject to homologous desensitization. ${ }^{54}$ The stimulation of the PI cycle by AngII is only very weak and transient. ${ }^{66}$ On the other hand, the increase in diacylglycerol level was highest after stimulation with AngII (unpublished data), suggesting that phospholipase D was activated in this case as well, as was observed earlier. ${ }^{69}$ Although cultured cardiomyocytes contain phorbol ester-stimulatable protein kinase $\mathrm{C}$, direct activation of the kinase by the agonists was only very weak (results not shown). However, activation of other kinases is plausible as shown by the phosphorylation of a 30-kDa nonmembrane-bound protein by PHE but not by either ET-1 or AngII or by stimulation with phorbol ester ${ }^{84}$ Noting these large differences in signal transduction it is not surprising to see that the ultimate hypertrophic response was not the same for the three agonists. ET-1 is the strongest inductor of hypertrophy as judged by protein/DNA ratio, closely followed by PHE. In contrast, AngII gave only a very weak hypertrophic response. ${ }^{59}$ Agonist-induced induction of hypertrophy was already apparent after $24 \mathrm{hrs}$, in contrast to the effect of protein kinase $C$ activation by phorbol ester where the protein/DNA ration was only increased after $48 \mathrm{hrs}$. The differences in ability to induce hypertrophy were also found when induction of transcription of the immediate genes $c$ fos, c-jun, c-myc and EGR-1 was studied. Furthermore, the well-known induction of fetal gene expression, illustrated by expression of the ANF gene, was again weakest after stimulation with AngII. Experiments where the effect of hypertrophy on the expression is studied of proteins involved in $\mathrm{Ca}^{2+}$ homeostasis were performed, and remarkable similarity with the effect of in vivo induction of hypertrophy was noted, especially in the case of sarcoplasmatic reticulum $\mathrm{Ca}^{2+}$ ATPase. ${ }^{59}$ These results indicate that induction of hypertrophy of cardiomyocytes in culture is a good model for studying signal transduction and genetic reprogramming.

\section{REFERENCES}

1. Ueno, H., M. B. Perryman, R. Roberts \& M. D. Schneider. 1988. J. Cell Biol. 107: $1911-1918$.

2. Boheler, K. R. \& K. Schwartz. 1992. Med. 2: 176-182.

3. VAN Bilsen, M. \& K. R. Chien. 1993. Cardiovasc. Res. 27: 1140-1149.

4. Baker, K. M., M. I. Chernin, S. K. Wixson \& J. F. Aceto. 1990. Am. J. Physiol. 259: H324-332.

5. Hannan, R. D., F. A. Stennard \& A. K. West. 1993. J. Mol. Cell. Cardiol. 25: $1137-1148$.

6. Ito, H., M. Hiroe, Y. Hirata, H. Fujisaka, S. Adachi, H. Akimoto, Y. Оhta \& F. MaRUMO. 1994. Circulation 89: 2198-2203.

7. Kojima, M., I. Shiojima, T. Yamazaki, I. Komuro, Z. Yunzeng, W. Ying, T. Mizuno, K. Ueki, K. Tobe, T. Kadowaki, R. Nagal \& Y. Yazaki. 1994. Circulation 89: 2204-2211.

8. Clark, W. A., S. J. Rudnick, J. J. Lapres, L. C. Andersen \& M. C. Lapointe. 1993. Circ. Res. 73: 1163-1176. 
9. Kubisch, C., B. Wollnik, A. Maass, R. Meyer, H. Vetter \& L. Neyses. 1993. FEBS Lett. 335: 37-40.

10. Neyses, L., J. Nouskas, J. Luyken, S. Fronhoffs, S. Oberdorf, U. Pfeifer, R. S. Williams, V. P. Sukhatme \& H. Vetter. 1993. J. Hypertens. 11: 927-934.

11. Sugden, P. H., S. J. Fuller, J. R. Mynett, R. J. Hatchett, M. A. Bogoyevitch \& M. C. Sugden. 1993. Biochim. Biophys. Acta 1175: 327-332.

12. Zierhut, W. \& H. G. Zimmer. 1989. Circ. Res. 65: 1417-1425.

13. Parker, T. G., S. E. Packer \& M. D. Schneider. 1990. J. Clin. Invest. 85: 507-514.

14. Parker, T. G., K.-L. Chow, R. J. Schwartz \& M. D. Schneider. 1990. Proc. Natl. Acad. Sci. USA 87: 7066-7070.

15. Fuller, S. J., J. R. Mynett \& P. H. Sugden. 1992. Biochem. J. 282: 85-90.

16. Ito, H., M. Hiroe, Y. Hirata, M. Tsujino, S. Adachi, M. Shichiri, A. Kolke, A. Nogami \& F. Marumo. 1993. Circulation 87: 1715-1721.

17. SiMPSON, P. 1985. Circ. Res. 56: 884-894.

18. Baker, K. M. \& J. F. ACETo. 1990. Am. J. Physiol. 259: H610-H618.

19. Shuberta, H. E., P. M. McDonough, A. N. Harris, K. U. Knowlton, C. G. GlemBotsk1, J. H. Brown \& K. R. ChiEN. 1990. J. Biol. Chem. 265: 20555-20562.

20. Suzukı, T., H. Hoshi \& Y. Mitsui. 1990. FEBS Lett. 268: 149-151.

21. Glembotski, C. C., C. E. Irons, K. A. Krown, S. F. Murray, A. B. Sprenkle \& C. A. SEI. 1993. J. Biol. Chem. 268: 20646-20652.

22. Komuro, I., Y. Katoh, T. Kaida, Y. Shibazaki, M. Kurabayashi, E. Нoh, F. TAKaKu \& Y. Yazaki. 1991. J. Biol. Chem. 266: 1265-1268.

23. McDermott, P. J. \& H. E. Morgan. 1989. Circ. Res. 64: 542-553.

24. Johnson, T. B., R. L. Kent, B. A. Bubolz \& P. J. McDermott. 1994. Circ. Res. 74: 448-459.

25. Knowlton, K. U., M. C. Michel, M. Itani, H. E. Shubeita, K. Ishihara, J. H. Brown \& K. R. Chien. 1993. J. Biol. Chem. 268: 15374-15380.

26. Lamorte, V. J., J. Thornburn, D. Absher, A. Spiegel, J. H. Brown, K. R. Chien, J. R. Feramisco \& K. U. Knowlton. 1994. J. Biol. Chem. 269: 13490-13496.

27. Buu, N. T., R. Hui \& P. Falardeau. 1993. J. Mol. Cell. Cardiol. 25: 1037-1046.

28. Sei, C. A., C. E. Irons, A. B. Sprenkle, P. M. McDonough, J. H. Brown \& C. C. Glembotski. 1991. J. Bjol. Chem. 266: 15910-15916.

29. McDonough, P. M., J. H. Brown \& C. C. Glembotski. 1993. Am. J. Physiol. 264: H625-H630.

30. Henrich, C. J. \& P. C. Simpson. 1988. J. Mol. Cell. Cardiol. 20: 1081-1085.

31. Mochly-Rosen, D., C. J. Henrich, L. Cheever, H. Khaner \& P. C. Simpson. 1990. Cell Regulation 1: 693-706.

32. Shubeita, H. E., E. A. Martinson, M. Van Bilsen, K. R. Chien \& J. H. Brown. 1992. Proc. Natl. Acad. Sci. USA 89: 1305-1309.

33. Bogoyevitch, M. A., P. J. Parker \& P. H. Sugden. 1993. Circ. Res, 72: 757-767.

34. Dunnmon, P. M., K. Iwaki, S. A. Henderson, A. Sen \& K. R. Chien. 1990. J. Mol. Cell. Cardiol. 22: 901-910.

35. Allo, S. N., P. J. McDermott, L. L. Carl \& H. E. Morgan. 1991. J. Biol. Chem. 266: 22003-22009.

36. KariYA, K. I., L. R. Karns \& P. C. Simpson. 1992. J. Biol. Chem. 266: 10023-10026.

37. Gruver, C. L., S. E. George \& A. R. Means. 1992. Trends Cardiovasc. Med. 2: 226-231.

38. Bogoyevitch, M. A., P. E. Glennon \& P. H. Sugden. 1993. FEBS Lett. 317: 271-275.

39. Thorndurn, A., J. Tornburn, S.-Y. Chen, S. Powers, H. E. Shubejta, J. R. Feramisco \& K. R. ChiEN. 1993. J. Biol. Chem. 268: 2244-2249.

40. Starkes, N. F., P. C. Simpson, N. Bishopric, S. R. Coughlin, W. M. F. Lee, J. A. Escobedo \& L. T. Williams. 1986. Proc. Natl. ACad. Sci. USA 83: 8348-8350.

41. Matiuck, N. V. \& J. L. Swain. 1992. Trends Cardiovasc. Med. 2: 61-65.

42. Iwaki, K., V. P. Sukhatme, H. E. Shubeita \& K. R. Chien. 1990. J. Biol. Chem. 265: $13809-13817$.

43. Kovačıč-Milivojević B. \& D. G. Gardner. 1992. Mol. Cell. Biol. 12: 292-301. 
44. Neyses, L., J. Nouskas \& H. Vetter. 1991. Biochem. Biophys. Res. Commun. 181: 22-27.

45. Meidell, R. S., A. Sen, S. A. Henderson, M. F. Slahetka \& K. R. Chien. 1986. Am. J. Physiol. 251: H1076-H1084.

46. Ikeda, U., Y. Tsutuya \& T. Yaginuma. 1991. Am. J. Physiol. 260: H953-H956.

47. Lee, H. R., S. A. Henderson, R. Reynolds, P. Dunnmon, D. Yuan \& K. R. Chien. 1988. J. Biol. Chem. 263: 7352-7358.

48. Knowlton, K. U., E. Baracchini, R. S. Ross, A. N. Harris, S. A. Henderson, S. M. Evans, C. C. Glembotski \& K. R. Chien. 1991. J. Biol. Chem. 266: 7759-7768.

49. McDonough, P. M. \& C. C. Glembotski. 1992. J. Biol. Chem. 267: 11665-11668.

50. Bishopric, N. H., P. C. Simpson \& C. P. Ordahl. 1987. J. Clin. Invest. 80: 1194-1199.

51. Long, C. S., C. P. Ordahl \& P. C. Simpson. 1989. J. Clin. Invest. 83: 1078-1082.

52. Bishopric, N. H. \& L. Kedes. 1991. Proc. Natl. Acad. Sci. USA 88: 2132-2136.

53. Waspe, L. E., C. P. Ordahl \& P. C. Simpson. 1990. J. Clin. Invest. 85: 1206-1214.

54. Van Heugten, H. A. A., K. Bezstarosti, D. H. W. Dekkers \& J. M. J. Lamers. 1993. J. Mol. Cell. Cardiol. 25: 41-52.

55. Ishikawa, T., L. L. Osamu, S. Kimura, M. Yanagisawa, K. Goto \& T. Masaki. 1991. Circ. Res. 69: 918-926.

56. Woodcock, E. A., S. L. LAnd \& R. K. Andrews. 1993. Clin. Exp. Pharmacol. Physiol. 20: $331-334$.

57. Bogoyevitch, M. A., P. E. Glennon, M. B. Andersson, A. Clerk, A. Lazou, C. J. Marshall, P. J. Parker \& P. H. Sugden. 1994. J. Biol. Chem. 269: 1110-1119.

58. Suzuki, T., H. Hoshi, H. Sasaki \& Y. Mitsui. 1991. J. Cardiovasc. Pharmacol. 17(Suppl. 7): S182-S186.

59. Lamers, J. M. J., H. S. Sharma, P. D. Verdouw \& H. A. A. Van Heugten. 1994. Can. J. Cardiol. 10(Suppl. A): 49A.

60. Ito, H., Y. Hirata, M. Hiroe, M. Tsujino, S. Adachi, T. Takamoto, M. Nitta, K. Taniguchi \& F. Marumo. 1991. Circ. Res. 69: 209-215.

61. Wang, D. L., J. J. Chen, N. L. Shin, Y. C. Kao, K. H. Hsu, W. U. Huang \& C. C. Liew. 1992. Biochem. Biophys. Res. Commun. 183: 1260-1265.

62. Irons, C. E., C. A. Sei \& C. C. Glembotski. 1993. Am. J. Physiol. 33: H282-H285.

63. Van Heugten, H. A. A., H. W. De Jonge, K. Bezstarosti \& J. M. J. Lamers. 1994. J. Mol. Cell. Cardiol. 26: 1081-1093.

64. Suzuki, T., T. Kumazaki \& Y. Mitsui. 1993. Biochem. Biophys. Res. Commun. 191: 823-830.

65. Sadoshima, J.-I. \& S. Izumo. 1993. Circ. Res. 73: 413-423.

66. Abdellatif, M. M., C. F. Neubauer, W. J. Lederer \& T. B. Rogers. 1991. Circ. Res. 69: 800-809.

67. Sadoshima, J.-I. \& S. Izumo. 1993. Circ. Res. 73: 424-438.

68. Lamers, J. M. J., H. W. De Jonge, V. Panagia \& H. A. A. Van Heugten. 1993. Cardioscience 4: 121-131.

69. Ito, H., Y. Hirata, S. Adachi, M. Tanaka, M. Tsujino, A. Kolke, A. Nogami, F. Marumo \& M. Hiroe. 1993. J. Clin. Invest. 92: 398-403.

70. Komuro, I., T. Kaida, Y. Shibazaki, M. Kurabayashi, Y. Katoh, E. Hoh, F. TaKAKU \& Y. YAZAKI. 1990. J. Biol. Chem. 265: 3595-3598.

71. Sadoshma, J.-I., L. Jahn, T. Takahashi, T. J. Kulik \& S. Izumo. 1992. J. Biol. Chem. 267: 10551-10560.

72. Yazakl, Y., I. Komuro, T. Yamazaki, K. Tobe, K. Maemura, T. Kadowakı \& R. NAGAI. 1993. Mol. Cell. Biochem. 119: 11-16.

73. Sadoshima, J.-I. \& S. IzUmo. 1993. EMBO J. 12: 1681-1692.

74. Dassouli, A., J.-C. Sulpice, S. Roux \& B. Crozatier. 1993. J. Mol. Cell. Cardiol. 25: 973-982.

75. Yamazaki, T., K. Tobe, E. Hoh, K. Maemura, T. Kaida, I. Komuro, H. Tamemoto, T. Kadowaki, R. NaGai \& Y. YaZAKI. 1993. J. Biol. Chem. 268: 12069-12076.

76. Sadoshima, J.-I., Y. XU, H. S. Slayter \& S. Izumo. 1993. Circulation 88: 1-190.

77. Sadoshima, J.-I., Y. Xu, H. S. Slayter \& S. Izumo. 1993. Cell 75: 977-984. 
78. Sadoshima, J.-I., T. Takahashi, L. Jahn \& S. Izumo. 1992. Proc. Natl. Acad. Sci. USA 89: $9905-9909$.

79. Komuro, I. \& Y. Yazaki. 1993. Annu. Rev. Physiol. 55: 55-75.

80. Chien, W. W., R. MohabiR \& W. T. Clusin. 1990. J. Clin. Invest. 85: 1436-1443.

81. Fantl, W. J., D. E. Johnson \& L. T. Williams. 1993. Annu. Rev. Biochem. 62: 453-481.

82. Sharma, H. S., P. D. Verdouw \& J. M. J. Lamers. 1994. Cardiovasc. Drugs Ther. 8: $461-468$.

83. Lamers, J. M. J. \& J. T. Stinis. 1979. Life Sci. 24: 2313-2320.

84. De Jonge, H. W., H. A. A. Van Heugten, K. Bezstarosti \& J. M. J. Lamers. Biochem. Biophys. Res. Commun. 203: 422-429. 